\title{
Managing Editor's Column
}

\author{
Vol. 26, No. 5
}

Dear Readers,

It is a great pleasure for me to introduce the second regular issues of 2020. As already highlighted, we have recently moved to the open license CC-BY-ND 4.0 and received many positive responses. Thus, we believe we can further increase the visibility of J.UCS, and combined with commitment to high quality research, we can further improve citation rate and impact factor. All of these achievements would not be possible without the generous support by our consortium members, our very supportive editorial board, the J.UCS team and most importantly the contributions of our authors. I'd like to thank all of them and look forward to further collaborations in the near future. I further want to extend our editorial board: if you are a tenured Associate Professor or above with a good publication record, please do apply for a membership in our editorial board. We are also interested in high quality proposals for special issues which cover emerging topics and new trends. If you are interested in editing a special issue, visit our information page at http://www.jucs.org/ujs/ jucs/info/special_issues/special_guidelines.html and send us a corresponding proposal to c.guetl@tugraz.at.

In this regular issue, I am very happy to introduce 4 accepted papers from 4 different countries.

Sana Debbech, Simon Collart-Dutilleul and Philippe Bon from France present in their research a real-world semantics interpretation and conceptualization of dysfunctional analysis related concepts based on the Unified Foundational Ontology (UFO) and other standards to avoid ambiguities applied for railway systems design.

Rastko Martać, Nikola Milivojević, Marijana Despotović-Zrakić, Zorica Bogdanović and Dusan Barać from Serbia investigates how to transform a manual monitoring in the context of water systems.

João Gabriel Lopes de Oliveira, Pedro Moreira Menezes da Costa and Flávio Luis de Mello from Brazil introduce their work on knowledge geometry in phenomenon perception and artificial intelligence presenting an approach that is able to describe the influence of scope, development paradigms, matching process and ground truth on phenomenon perception. 
Ricardo Pérez-Castillo, Ignacio García-Rodríguez de Guzman, Mario Piattini, and Moisés Rodriguez from Spain presents a new vision of teaching in the area of IS audit presenting a methodology based on project based learning which simulates that students belong to a real organization where they must not only develop an Internal Control but also evaluate it through IS Audit techniques.

Enjoy Reading!

Cordially,

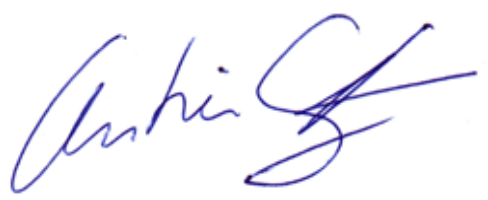

Christian Gütl, Managing Editor

Graz University of Technology, Graz, Austria

Email: c.guetl@tugraz.at 